\title{
INTRODUÇÃO AO ESTUDO DO QUATERNÁRIO DO LITORAL DO ESTADO DA BAHIA - TRECHO SALVADOR ILHEUS
}

Louis Martins

Abílio S. Vilas Boas

Jean Marie Flexor

\begin{abstract}
The extension of the brazilian coast between Salvador and Ilhéus (Bahia) shows evidences of two distinct episodes of transgression in the Quaternary, deduced from the observation of sandy littoral deposits above the present mean sea level: (a) one, older, related to the event of 120.000 years B.P. (Late Pleistocene), and (b) the other, more recent, related to the end of the last great transgression (Holocene). After the deposition of the Barreiras Formation (Pliocene) under a

continental and dry climate, followed period of humid climate, succeded by a new dry period, when a new detritic continental formation has been deposited. Before the maximum of the last but one transgression (120.000 years B.P.), the climate became humid again, and since that time it has not presented any appreciable variation.

The Quaternary deposits have been submitted, locally, to deformations connected to sinking and tilting of blocks.
\end{abstract}




\section{INTRODUÇÃO}

A regiåo do litoral brasileiro aqui estudada está compreendida aproximadamente entre os paralelos de $13^{\circ}$ e $15^{\circ}$ de latitude $S$ (Figura 1).

Geologicamente ela é caracterizada pela bacia de afundamento do Recôncavo e suas dependências para o sul encaixa* das, segundo uma direçăo NNE-SSW, na dorsal precambriana do Brasil oriental. Esta dorsal é constituída por séries metamorficas e sedimentares de idades variadas que foram afetadas por uma tectônica paleozóica de arqueamentos e basculamentos de grande raio de curvatura, podendo localmente passar a falhamentos. A fossa de afundamento do Recôncavo começou a se individualizar no Jurássico com um apêndice do "rift" que deu nascimento ao atlântico sul, através da separação da África e da América do Sul. Na zona litoral essa graben é limitado a leste pela falha de Salvador cujo rejeito é de 4.000 metros e, a oeste, pela falha de Maragogipe, com rejeito de 300 metros. A fossa foi preenchida a partir do Jurássico Superior por sedimentos areno-argilosos compreendendo variaçðes bruscas de fácies. Esses sedimentos podem atingir uma espessura de 4.000 metros e såo em grande parte de origem deltaica. $O$ fim do Terciário foi marcado pela deposição da Formação Barreiras que recobriu tanto as formaçóes precambrianas quanto as cretáceas e se estendeu provavelmente sobre uma parte da plataforma continental, como é o caso da região de Prado, no sul do Estado. Durante o Quaternário, caracterizado por variaçðes importantes do nível do mar e do clima, se depositaram formaçðes em estreita ligação com esses dois fenômenos. $\mathrm{O}$ objetivo principal do presente trabalho é exatamente cartografar essas formaçðes no trecho do litoral considerado.

Durante todo o Cretáceo a atividade tectônica, caracterizada por jogos de blocos alinhados na direção NNE-SSW, permaneceu bastante forte, diminuindo progressivamente de intensidade no fim do mesmo. Pouco a pouco a fossa foi cessando de se individualizar do resto da dorsal tornando-se solidária com os movimentos de grande raio de curvatura que caracterizam esta última. Entretanto, no fim do Terciário, algumas reativaçðes de falhas afetaram as formaçōes cretáceas. Em seguida, a fossa passou a se incorporar cada vez mais ao resto da dorsal, ao tempo em que as grandes linhas de fraturamento que a caracterizam tiveram a tendência a se cicatrizar e os movimentos verticais a cessar. Um outro objetivo deste trabalho é de averiguar se movimentos recentes afetaram as formaçoes marinhas quaternarias.

A morfologia atual da regiăo estudada foi profundamente marcada pela presença da bacia de afundamento e por sua tectônica especial, ligada a movimentos verticais acompanhados de basculamentos.

A leste, a cidade do Salvador está situada sobre um bloco em relevo do embasamento cristalino, que é separado das formações sedimentares do Cretáceo pela falha de Salvador.

A Baía de Todos os Santos e as zonas baixas que a prolonga em direção ao sul são inteiramente situadas sobre as formações sedimentares do Cretáceo. $O$ fato da baía estar situada sobre rochas sedimentares encaixadas em rochas cristalinas favorece a hipótese de uma origem por erosão diferencial para a mesma. Entretanto, um estudo da rede hidrográfica em torno da baía mostra que a drenagem em direçăo à mesma é embrionária. Efetivamente, a linha de divisăo das águas se situa a 1 ou $2 \mathrm{~km}$ das suas margens. Essa disposiçăo é uma indicação de erosão diferencial insignificante. $O$ rio Paraguaç, cuja desembocadura se situa no lado da costa oeste da baía, tem a quase totalidade do seu curso sobre rochas precambrianas, nåo podendo, portanto, ser responsável pela escavação da baía por erosão diferencial. E necessário desse modo admitir que a formação da baía é relativamente recente pois a rede hidrográfica ainda năo foi afetada pela sua presença (Tricart e Cardoso da Silva, 1968). A
Baía de Todos os Santos corresponde provavelmente a um compartimento abaixado ou, melhor, ao abaixamento de uma série de blocos que podem ter tido reaçôs ligeiramente diferentes entre si.

A oeste, o embasamento cristalino reaparece separado das formações cretáceas pela falha de Maragogipe. Frequentemente, ao pé desta, aparece uma zona baixa que pode, como nas regioes de Maragogipe, Valença - Nilo Peçanha e Ituberá, ser ocupada por lagunas (Figura 1).

A parte do litoral situada sobre a bacia sedimentar termina na desembocadura do rio de Contas, que está situada sobre uma falha.

A partir de Itacaré o litoral está situado sobre o embasamento cristalino. Os depósitos quaternários aí existentes são de pequena extensão, com exceção daqueles localizados na regiāo da pequena bacia sedimentar de Almada, que corresponde a uma zona afundada no meio do embasamento cristalino.

\section{FORMAČ̃̃ QUATERNÁRIA CONTINENTAL}

Na costa oeste da Baía de Todos os Santos, nas regioes de Salinas das Margarinas e Saubara (Fig. 2), såo encontrados dois afloramentos importantes de uma formação arenosa com seixos cujos grãos, mal selecionados, apresentam características continentais. Vestígios dessa mesma formaçăo aparecem nas ilhas do Medo, Itaparica, Matarandiba e Carapeba (Fig. 2).

A interpretação fotogeológica da área do trabalho sugere a ocorrência dessa formaçăo em outras regiðes, notadamente nas ilhas do Frade e de Maré e na Ponta de Areia (Fig. 2). E razoável pensar que esses diversos afloramentos sejam restos de uma formação de grande extensão e que deve ter recoberto a maior parte da região atualmente ocupada pela Baía de Todos os Santos, como pode ser sugerido pela presença de sedimentos relictos com características continentais no fundo do Canal de Itaparica (Bittencourt, Ferreira e Di Napoli, 1976). Fora da baía, podem ser encontrados depósitos arenosos equivalentes ao norte de Valença, ao norte de Maraú (Fig. 3) e ao norte de Salvador. Existe grande probabilidade de que as grandes dunas brancas situadas em Itapua, ao norte de Salvador, sejam resultantes do retrabalhamento pelo vento da parte superior dessa formação. Nesse caso, a origem dessas dunas năo estaria diretamente ligada à presença do mar, sendo muito mais antigas do que a ultima transgressão.

Localmente, segundo a regiăo de ocorrência, as areias dessa formação continental podem ter sido originadas a partir do retrabalhamento de sedimentos do Barreiras, das formações cretáceas ou da alteração das rochas precambrianas. As suas características texturais e mineralógicas variam em função dessas diversas fontes. Em algumas regioes, onde a fonte foi indiscutivelmente o cristalino, os depósitos săo arcosianos com constituintes quartzosos muito angulares e fragmentos de feldspato em vias de alteraça. Nas zonas onde a fonte principal foram as rochas do Cretáceo, fragmentos de arenitos e folhelhos constituem em grande parte a fraçăo rudácea dos depósitos. Em alguns afloramentos aparecem seixos de quartzo bem arredondados e bastante semelhantes aos seixos presentes em certas fácies do Barreiras.

Tendo em vista as condições climáticas atuais e o tipo de vegetação existente, os cursos d'água dessa parte do litoral onde aflora a formação continental transportam muito pouco material grosseiro. Considerando as características e extensão desses depósitos, a sua formação, ocorrida durante uma época de nível de mar baixo, só pode ser atribuida a uma deposição em lençol ("épandage en nappe"\%, o que implica em condiçóes climáticas totalmente diferentes das 


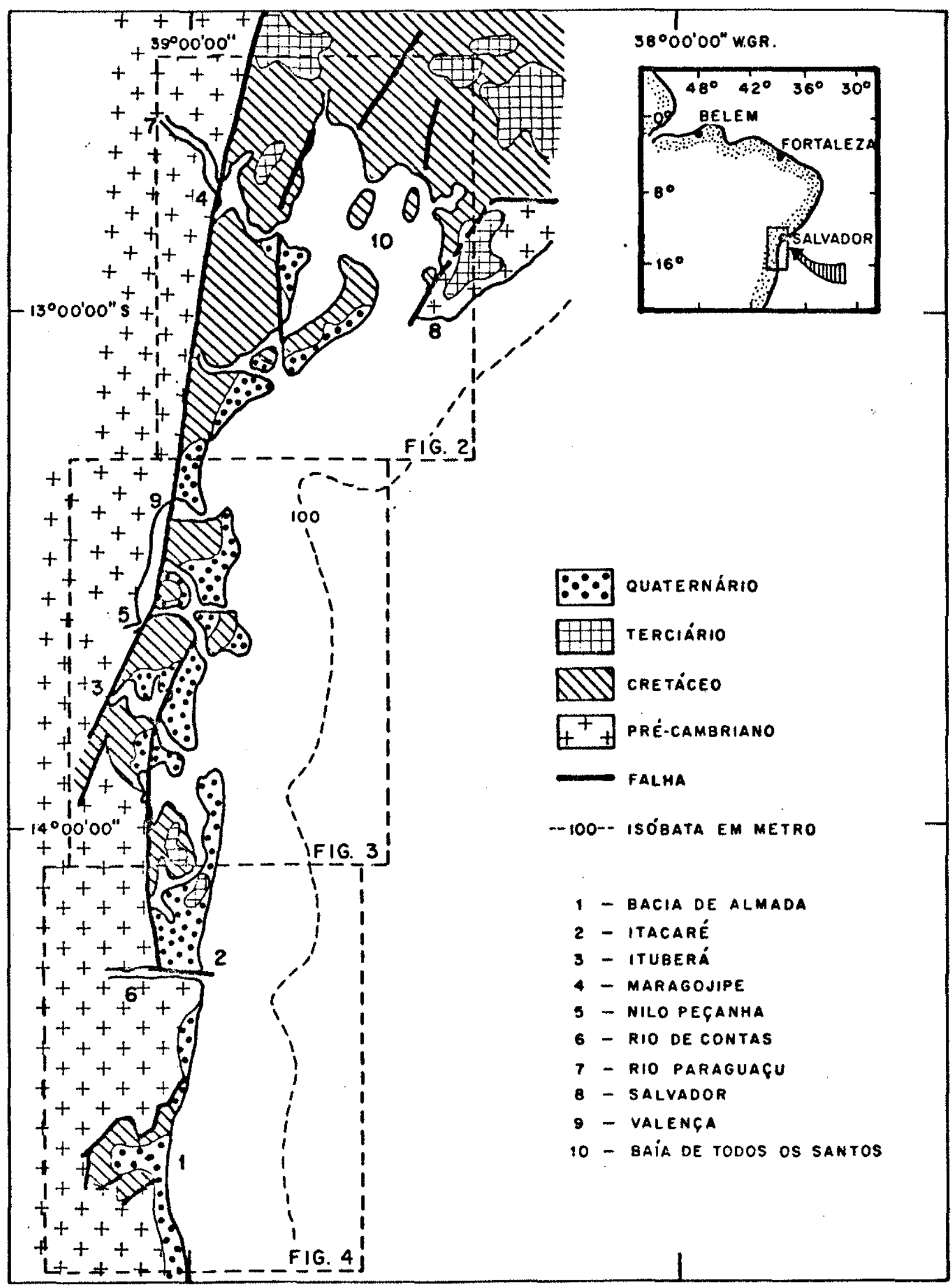

Figura 1 - Mapa geológico geral da área estudada. As áreas tracejadas mostram a articulação das Figs. 2, 3 e 4 que serão discutidas adiante no texto 




Figura 2 - Mapa geológico da região circunvizinha à Baía de Todos os Santos 


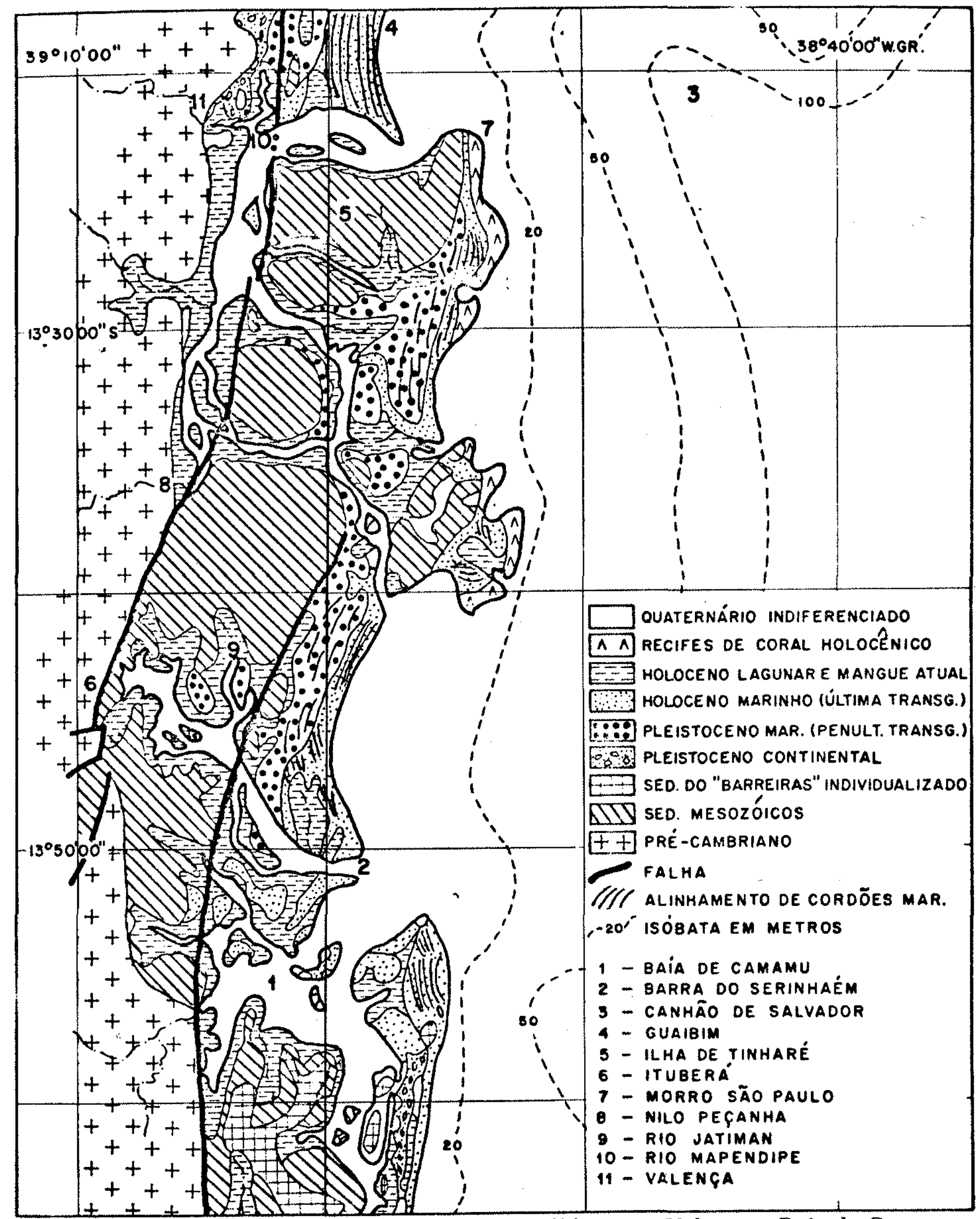

Figura 3 - Mapa geológico da região compreendida entre Valença e Baía de Camamu 
condições atuais, isto e, clima mais seco com chuvas mais concentradas e violentas.

$O$ fato de que o Barreiras tenha en alguns casos servido de fonte a essas areias prova que elas são mais recentes do que o mesmo. Por outro lado, como será discutido mais adiante, o fato dessa formação continental ter sido retrabalhada pela penúltima transgressão mostra que a mesma é mais antiga que essa, no máximo da qual o nível relativo do mar foi superior ao nível médio atual.

\section{FORMAÇÃO QUARTERNARIA MARINHAS}

Uma cartografia de detalhe e datações absolutas de amostras com $\mathrm{C} 14$ permitiram a diferenciação de duas formaçðes quaternárias marinhas. A mais recente está indiscutivelmente ligada à fase terminal da última grande transgressão e será aqui referida como formaçăo holocềnica. A mais antiga, aqui mencionada como formação pleistocênica marinha foi provavelmente depositada durante a penúltima grande transgressåo, que atingiu um nível relativo superior ao nível atual do mar. Segundo os dados da literatura o máximo desse episódio se situa em torno de 120.000 anos B.P. As únicas dataçoes que puderam ser obtidas sobre amostras desta formação foram as seguintes; a) um pedaço de madeira coletado numa camada argilosa, apresentando idade 30.000 anos B.P. (Bah -562 ) e b) fragmentos de madeira amostrados em areias fortemente impregnadas de substâncias húmicas secundárias, apresentando uma idade de $27.165-1.775$ anos B.P. (Bah - 563). Esta última amostra está situada em um material muito permeável, diferentemente do que ocorre com Bah - 562, e que portanto deve ter sido muito impregnada por ácidos húmicos recentes. Assim, é bem provável que a fraca radioatividade detectada corresponda a uma contaminaçăo por carbono recente que nåo pode ser eliminado completamente pelos pré-tratamentos com $\mathrm{NaOH}$ a quente. Com efeito, uma ligeira contaminaçăo por carbono recente numa amostra "morta" pode gerar a radioatividade correspondente àquela idade medida. Deve-se pois considerar as idades próximas do limite de dataça pelo radiocarbono com o maior cuidado. Sxo conhecidos, na literatura, numerosos exemplos de amostras datadas em cerca de 30.000 anos B.P. com C14 e que, novamente datados com o método $\mathrm{U} / \mathrm{Th}$, apresentaram idades da ordem de 120.000 B.P.

Por outro lado, há também a possibilidade da formação pleistocênica marinha estar ligada a um período transgressivo mais antigo que o penúltimo. Se fosse o caso, entretanto, dever-se-ia encontrar entre os testemunhps daquele e os do Holoceno outras formaçðes intermediárias, o que nunca ocorre em toda a área.

\section{TESTEMUNHOS DA TRANSGRESSÃO PLEISTOCENCIA}

\section{CARACTERISTICAS}

A parte final da penúltima grande transgressăo que a seguiu deixaram, sobre a parte do litoral entre a ilha de Itaparica e a desembocadura do rio de Contas (Figs. 2, 3 e 4), testemunhos bastante importantes. Tratam-se de depósitos arenosos comumente de cor marron a preta. Essas coloraçðes são devidas à presença de matéria orgânica e de ferro disseminados, de origem secundária. A origem marinha desses depósitos é atestada pela presença, em certas regiøes, de antigas cristas de cordôs litorâneos evidenciadas nas fotogratias aéreas. E interessante observar que esses cordoes antigos apresentam um aspecto caracterizado por largas zonas intercordoes, enquanto que as cristas dos cordoes encontrados na formação holocênica são muito mais finas e estreitamente próximas e paralelas. Eles såo igualmente mais elevados (6 a 8 metros) do que os cordoes holocênicos (aproximadamente 3 metros). Essas características permitem fazer uma primeira diferenciação entre os dois tipos de formaçōes marinhas quaternárias. Nas regioes onde cristas de cordōes não aparecem, foram encontrados tubos fósseis de Callianassa, como na Formação Cananeia, do sul do litoral paulista (Suguio e Martin, 1976). Estando a zona de vida desses artrópodes marinhos limitada à parte inferior da regiăo intermaré, tem-se uma confirmação definitiva da origem marinha litoral desses depósitos arenosos. observamse também estruturas cruzadas que são igualmente características dessa parte da baixa praia. Em certos lugares, notadamente ao sul de Maraú, pode-se observar na formação arenosa a presença de pequenas lentes de restos vegetais. A presença dessas lentes igualmente observadas por Suguio e Martin (1976) na Formação Cananeia ao sul do Estado de São Paulo, não está em contradição com uma origem marinha. Dessa forma, perto de Campinho, na Baía de Camamu (Fig. 3), observam-se tais depósitos em vias de formação, na parte baixa da praia de uma pequena baía atual. Efetivamente, na parte inferior da zona intermaré, sobre um substrato arenoso horizontal (podendo conter tubos de Callianassa), observou-se uma acumulação de restos vegetais que estava sendo recoberta por um banco arenoso, cujo desclocamento origina estruturas cruzadas. Na mesma região nota-se a existência de outros grandes bancos arenosos. seguramente móveis, cujos deslocamentos poderiam dar origem a estruturas cruzadas de grandes dimensðes, bastante semelhantes àquelas encontradas ao sul de Maraú.

Deve-se mencionar que em certas partes esses depósitos arenosos apresentam na superficie vestígios de cristas de cordões litorais, enquanto que em outras os mesmos năo săo encontrados. E possível pensar-se que eles nunca tenham existido onde não são observados atualmente. Com efeito, deve-se levar em conta que durante a fase transgressiva o material arenoso foi sendo depositado sem a formação de cordōes, que só se instalaram na fase regressiva subsequente. Em locais protegidos, de águas calmas, com pouca energia, principalmente nas partes mais interiores de baías, entretanto, mesmo durante a regressão aquelas feições não chegaram a ser formadas. Na realidade, constatarse que as partes sem cordðes estão situadas exatamente nas zonas internas de paleobaias, invadidas pelo mar na ocasiăo do máximo da transgressåo. Os cordðes começaram a se formar um pouco depois de alcançado o máximo, a partir de uma restinga original que teve a tendência de fechar a baía deixando no interior toda uma região sem cordóes litorâneos.

\section{REPARTICAOO GEOGRAFICA}

Até aqui ainda não foi encontrado nas bordas da Baía de rodos os Santos nenhum testemunho da penúltima transgressão situado acima do nivel atual do mar.

Sobre a costa oceânica da ilha de Itaparica, na altura de Barra do Gil e Conceiçåo (Fig. 2), um testemunho de pequena extensão foi preservado da erosão. Ao longo do Canal de ltaparica, na ilha de Carapeba e possibelmente na própria ilha de Itaparica, devem existir igualmente outros testemunhos da formação pleistocênica marinha (Fig. 2). Entre a ponta de Caixa Pregos e a barra do rio Jequiriçá existe um grande afloramento que apresenta na sua parte externa cristas de cordðes bem nítidas (Fig. 2). Não foi possível observar no campo se essa formação marinha se apoia diretamente sobre o Cretáceo ou sobre a formação continental arenosa quaternária.

Entre a barra do rio Jequiriçá e Valença (Figs. 2 e 3) a formação pleistocênica marinha, com cristas de cordoes, está 


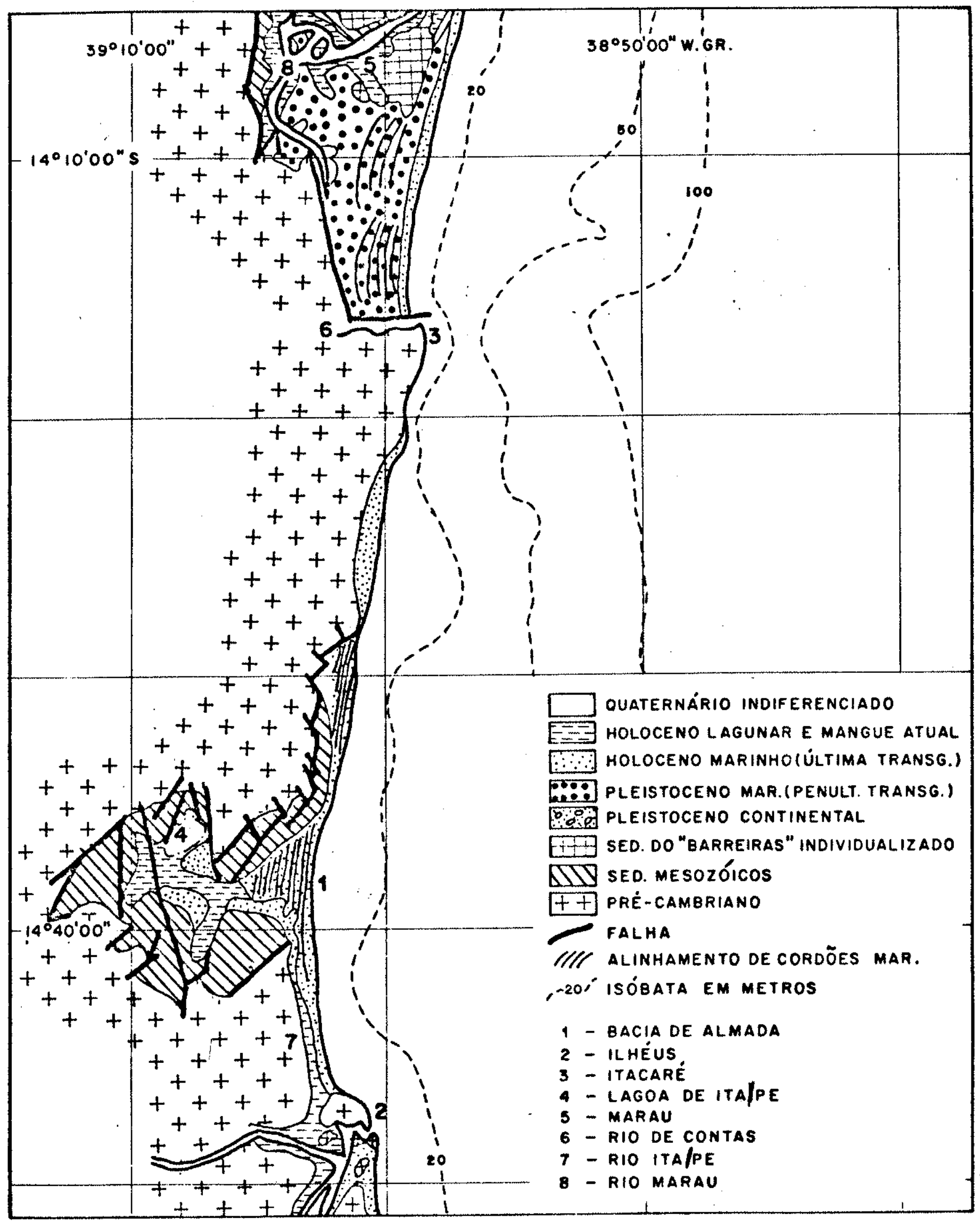

Figura 4 - Mapa geológico da regiāo compreendida entre Maraú e Ilhéus 
deslocada para o interior em relação aos outros afloramentos que a enquadram a norte e a sul. Nessa região, a formação marinha chega praticamente ao pé do cristalino. Entretanto, ao norte de Valença, verificou-se que existe entre o cristalino e a formação pleistocênica marinha um depósito arenoso formado de grãos mal selecionados característicos de uma origem continental.

Entre o Morro de São Paulo e a barra do rio Serinhaém (Fig. 3) a formação pleistocênica marinha é praticamente contínua, atingindo um grande desenvolvimento. $\mathrm{Na}$ maior parte da área ela parece se apoiar diretamente sobre o Cretáceo. Na regiåo de Ituberá, nas margens do rio Jariman (afluente da margem direita do rio Serinhaém) ela repousa sobre uma formação argilo-arenosa rica em seixos, de origem continental. E interessante notar que entre Valença e Nilo Peçanha năo foram encontrados depósitos marinhos pleistocênicos nos bordos da zona lagunar que se estende ao pé do cristalino, embora sejam os mesmos encontrados num mesmo paralelo, ao norte de Valença (Fig. 3).

Importantes afloramentos pleistocênicos marinhos foram encontrados ao sul de Maraú (Fig. 4). Esses afloramentos formam uma vasta planície arenosa praticamente horizontal, cuja parte externa possui cristas de cordões muito bem marcadas. Na parte interna (sem dordzes) foi possível observar tubos fósseis de Callianassa, notadamente nas margens do rio Maraú.

Recentemente, dentro de um projeto visando avaliar a possibilidade de uma retomada de exploração de uma rocha carbonobetuminosa de origem algal, conhecida desde muito tempo sob o nome de Marauíto, a CPRM estudou em detalhe a região de Maraú (CPRM, 1976). As camadas carbonobetuminosas estão intercaladas em arenitos pouco consolidados de cor marron a preta, situados na base do Barreiras. Nesse trabalho, os mesmos autores atribuem também uma origem continetal de idade pré-Barreiras à planície arenosa horizontal (sem a presença de cordðes) que se estende ao sul de Maraú, baseando-se nos seguintes critérios: a) cor escura semelhante àquela da rocha contendo as camadas carbonobetuminosas, b) presença de matéria orgânica disseminada, c) presença de lentes de restos vegetais e d) presença de estruturas oblíquas (cruzadas). Como já foi discutido anteriormente, essa matéria orgânica é de origem secundária, e as presenças de camadas com restos vegetais e de estruturas cruzadas não são critérios determinantes para a atribuição de uma origem continental para esses depósitos. Além disso, foram encontrados tubos fósseis de Callianassa que são característicos de depósitos da parte inferior da zona intermaré. Por outro lado, correlacionando esses depósitos arenosos com a rocha contendo marauito e atribuindo-os uma idade pré-Barreiras, torna-se dificil compreender como o Barreiras poderia ter sido erodido deixando uma superficie de erosăo horizontal como a que se observa atualmente. Somente o mar poderia, a rigor, fazê-lo, mas ele teria nesse caso deixado os testemunhos da sua passagem. Os pequenos afloramentos do Barreiras que se encontram na planície arenosa não estão situados sobre a mesma, como aparece no trabalho da CPRM (1976). Ao contrário, eles são antigos morros testemunhos que formavam ilhas no momento do máximo da penúltima transgressão e que foram englobados nos sedimentos arenosos litorâneos. Esses últimos não são, portanto, de idade pré-Barreiras mas pós-Barreiras.

Uma interpretação lògica que se pode admitir para essa regiăo é de que a Formaçăo Barreiras foi erodida deixando alguns morros testemunhos em uma época anterior à penúltima transgressão. No curso desta, o mar penetrou nessa zona baixa formando uma vasta baía onde se depositaram os sedimentos arenosos. Após sua emersão, durante a regressão seguinte, a vegetação se instalou sobre essas areias. Sendo a drenagem incipiente, o que se pode constatar ainda hoje, os ácidos húmicos e o ferro impregnaram as areias dando-lhes a sua coloração escura atual e originando uma consolidação mais ou menos intensa.
É conveniente esclarecer que năo se coloca aqui em dúvida a idade pré-Barreiras ou pelo menos da base do Barreiras para a formação contendo o Marauito "senso stricto" (isto é. a rocha carbonobetuminosa). Entretanto, a vasta planície arenosa horizontal que se estende ao sul de Maraú representa uma formação totalmente diferente, que é a formação pleistocênica marinha.

Foi feito um rápido reconhecimento na regiaxo compreendida entre as cidades de Itacaré e Ilhéus (Fig. 4) onde existem, ao norte da última, alguns vestígios dessa formação entre o embasamento cristalino e o rio Itaipe (Almada).

\section{TESTEMUNHOS DA TRANSGRESSÃO HOLOCÊNICA}

\section{CARACTERISTICAS}

Em certas regiões são encontradas incrustações de Vermetidae situadas acima do nível de vida atual da espécie. Pelo fato desses organismos terem uma zona ecológica bem definida, no limite superior da região infralitoral, torna-se fácil determinar com exatidão a altitude dos Vermetidae fósseis em relação ao nível atual da espécie. Por outro lado; a extensão vertical dos concrecionamentos é pequena, da ordem de $50 \mathrm{~cm}$, sobretudo em regiōes protegidas da ação de ondas fortes. Finalmente, seu nível biológico situa-se bastante próximo do nível médio do mar, de sorte que são sem fundamento as objeções quanto a utilização desses organismos fósseis baseando-se no fato de que pode ter havido uma variação recente na amplitude da maré no local considerado (Laborel, 1967).

Encontram-se igualmente numerosos buracos de ourico (Echinometra) situados acima da zona ecológica desses organismos. Esses testemunhos apresentam o inconveniente de não poderem ser datados.

Em certas partes do litoral existem recifes de coral mortos que estão em parte recobertos por cordðes arenosos. Eles testemunham antigos níveis marinhos situados acima do nível atual do mar. Entretanto, como a extensăo vertical dos corais é bastante grande, somente poderá ser definido o limite inferior dos niveis marinhos fósseis. Assim, somente se poderá saber que. na época em que viviam os corais, o nível do mar não podia ser inferior ao limite superior do nível biológico da espécie.

Existem igualmente numerosas incrustaçoes de algas calcárias situadas acima da zona ecológica da espécie. Para essas amostras a determinação dos níveis marinhos fósseis apresenta os mesnos problemas dos corais.

Finalmente, pode-se encontrar em alguns pontos do litoral terraços marinhos arenosos e depósitos lagunares podendo conter amostras datáveis ao $\mathrm{Cl}$. Comparados aos depósitos similares atuais, essas formações se situam de alguns centímetros a alguns metros mais altos que esses, testemunhando, portanto, antigos níveis do mar mais elevados do que o nível atual.

\section{REPARTICATO GEOGRAFICA}

\section{Costa Atlântica de Salvador}

Sobre os promontórios rochosos do porto da Barra (Fig. 2) uma incrustação de Vermetidae fixada na rocha indica um antigo nível marinho situado a $4,5-0,5 \mathrm{~m}$ acima do nível médio atual do mar. Duas outras incrustraçoes situadas na mesma zona testemunham antigos níveis elevados a $3-0,5$ $\mathrm{m}$ e $1-0,5 \mathrm{~m}$. A zona de vida desses Vermetidae entretanto, estanto eles situados em zonas de mar batido, poderia ter sido um pouco mais elevada que o normal. No momento, essas amostras eståo em processo de dataçăo.

$\mathrm{Na}$ zona intermaré da praia do Clube Espanhol (próximo 
ao Rio Vermelho, Fig. 2) pode-se observar um arenito de praia apresentando evidentes estratificaçðes mergulhando, de um lado, em direçăo ao continente e, do outro, em direçăo ao mar. Tendo em vista a posição desse arenito, próximo ao pé de uma falésia, trata-se certamente de um depósito de alta praia que testemunha um antigo nível marinho inferior ao nível atual. Infelizmente não foram encontradas nesse depósito conchas que permitissem fazer uma datação.

Na praia da Paciência (Rio Vermelho) foi possível coletar conchas em um grande arenito de praia. As características sedimentológicas indicam um depósito de uma zona de baixa praia (Ferreira, 1969). Neste local o arenito de praia testemunha um antigo nível marinho situado a $1,7 \pm 0,5 \mathrm{~m}$ acima do nível médio atual. Essas conchas foram datadas de $6610 \pm$ 180 (Bah. 510) e $6645 \pm 130$ anos B.P. (Bah. 235). E importante observar que as conchas năo estão em posição de vida podendo portanto, serem mais antigas do que a época do seu soterramento nas areias que originaram o arenito da praia. Foram também coletadas várias amostras de incrustações de Vermetidae, sendo que o mais elevado se situa a 3,8 $\pm 0,5 \mathrm{~m}$ acima da zona ecologica atual da espécie. Entretanto, como essa amostra se encontra em uma zona de mar batido, o limite superior ecológico desses Vermetidae pode ter sido elevado nesse local.

Em um promontório rochoso localizado na praia da Boca do Rio (Fig. 2) são encontradas incrustaçð̃es de Melobesiae, que testemunham um antigo nível marinho situado no mínimo a $2,4 \pm 0,5 \mathrm{~m}$ acima do nível médio do mar e que foi datado de $2295 \pm 85$ anos B.P. (Bah. 494). Por fim, os pequenos vales situados entre a Boca do Rio e I tapuã contêm sedimentos marinhos ou lagunares ricos em conchas que foram depositados durante os períodos onde o nível do mar foi superior ao nível atual. As conchas encontradas nas regiōes mais distantes da costa atual deverão permitir a datação de um período de máximo transgressivo.

\section{Bata de Todos os Santos}

Uma das características da baía é o fraco desenvolvimento ou ausência de formações holocênicas marinhas ou lagunares situadas acima do nível do mar (Fig. 2). Efetivamente, na maioria das vezes, as formações do Cretáceo vêm diretamente de encontro ao mar sem a intercalação de nenhum depósito quaternário, a não ser as zonas de mangue.

Em Itapagipe (Fig. 2), um antigo banco de areia contendo acamadamento frontal progradante foi fossilizado por cimentação. No momento da sua deposição, datada de 3270 土 145 anos B.P. (Bah. 415), o nível relativo do mar devia ser superior de aproximadamente $1 \pm 0,5 \mathrm{~m}$ do nível médio atual.

A parte externa das pequenas planícies de Paripe e São Tomé de Paripe (Fig. 2) é ocupada por terraços marinhos pouco elevados. Os níveis conchíferos datados de $2550 \pm 100$ anos B.P. (Bah. 409) e 210070 anos B.P. (Bah. 413) indicam antigos níveis marinhos vizinhos ou ligeiramente superiores ao nível atual (menos de 1 metro).

$O$ afloramento mais interessante se situa no lugar chamado Pedra Oca, em Periperi (Fig. 2). Nesse local uma incrustaçðo de Vermetidae fixado sobre arenitos do Cretáceo indica um antigo nível marinho situado a $3 \quad 0,5 \mathrm{~m}$ acima do nível médio atual. Sobre um terraço de abrasão nos sedimentos cretáceos encontra-se uma aniga praia sobre a qual foi construído um sambaquí, cujas conchas da base foram datadas de 2830130 anos B.P. (Si. 470) (Calderon, 1964) e $2630 \quad 110$ anos B.P. (Gif. 878) (Radiocarbon, 1971). A ponta rochosa de Pedra Oca está atualmente em erosåo, sendo muito provável que uma parte do sambaqui tenha sido destruída, tornando-se dessa forma dificil de se conhecer a posição da base do mesmo em relação ao nível da maré alta atual. Segundo Calderon (comunicação oral) uma parte do sambaqui estava situada na zona intermaré. A base da parte preservada da erosåo se situa a $0,8 \mathrm{~m}$ acima do nível da preamar atual. Em torno de 2800 anos B.P. o nível relativo do mar não poderia, portanto, ser superior a $0,8 \mathrm{~m}$ do nivel atual ou mesmo a $0,5 \mathrm{~m}$ se se considerar que o sambaqui foi construído ligeiramente acima do nivel da preamar. Proximo a esse primeiro depósito observa-se, repousando sobre o Cretáceo, um terraço marinho rico em conchas, que testemunha um antigo nivel marinho situado a $2,5 \pm 0,5 \mathrm{~m}$ acima do nível médio atual. Parece que os restos de um outro sambaqui ocupam o topo desse terraco.

Uma parte da ilha de Madre de Deus (Fig. 2) é ocupada por um terraço marinho holocênico com conchas que, coletadas na parte inerna do terraço a $2,3 \mathrm{~m}$ acima do nível atual da preamar, foram datadas de $3550 \pm 120$ anos B.P. (Bah. 269) e 3450120 anos B.P. (Bah. 270). Sobre a praia atual a maior concentraçăo de conchas é encontrada na zona de ruptura da declividade, que aí se situa a $0,7 \mathrm{~m}$ sob o nível da preamar. Baseando-se nessa constatação pode-se admitir que o topo desse terraço representa um antigo nível médio marinho que se situava a $3 \pm 0,5 \mathrm{~m}$ acima do nível atual. Uma outra amostra coletada na parte externa do terraço (próximo da baía) foi datada đe $2400 \pm 90$ anos B.P. (Bah. 246). Ela testemunha um antigo nivel marinho situado a 1,5 $\pm 0.5 \mathrm{~m}$ acima do nível atual.

Encontram-se também testemunhos de antigos niveis marinhos holocênicos na parte nordeste da ilha de Itaparica. Assim, em Porto Santo (Fig. 2), pode-se observar um pequeno terraço marinho muito rico em conchas cujo topo se situa a $2,6 \mathrm{~m}$ acima do nível da preamar atual. $E$ interessante notar que a margem interna da ilha (voltada para o canal de Itaparica) não apresenta depósitos marinhos situados acima do nível médio atual do mar.

\section{Costa atlântica ao sul da Baía de Todos os Santos até Itacaré}

Nessa parte do litoral os depósitos marinhos holocênicos são bem desenvolvidos (Figs. 3 e 4).

A costa oceânica da ilha de ltaparica é ocupada, a partir de Mar Grande para o sul (Fig. 2), por um terraço arenoso com cristas de antigos cordðes litorâneos que pode atingir $2 \mathrm{~km}$ de largura e cujo topo indica um antigo nível marinho situado a aproximadamente $4 \mathrm{~m}$ acima do nível médio atual. $\mathrm{Na}$ Ponta da Penha (Fig. 2), Laborel (1967) datou uma incrustaça de Vermetidae fixada sobre um afloramento do Cretáceo de $2430 \pm 95$ anos B.P. (Gif. 1933) (Delibrias e Laborel, 1969). Esses Vermetidae testemunham um antigo nível médio marinho situado a $2 \pm 0,5 \mathrm{~m}$ acima do nivel atual. Nessa parte da ilha existe um antigo recife coralino morto que testemunha um antigo nivel marinho superior ao atual. Na localidade de Conceição (Fig. 2) foi possível coletar uma amostra de coral sob os cordðes arenosos do terraço. Nesse local o topo do recife se situa a $1,9 \mathrm{~m}$ acima do nível da baixa-mar indicando, portanto, um antigo nível médio marinho situado pelo menos, a $1,5 \mathrm{~m}$ do nivel atual.

Entre a desembocadura do rio Jequiriçá e Valença (Figs. 2 e 3) o terraço marinho holocênico, com cordðes muito bem marcados, atinge uma largura de 4 a $5 \mathrm{~km}$. Sobre a margem esquerda do rio Jequiriçá, próximo ao contato com a formação marinha pleistocênica, o topo do terraço holocênico se situa de 2,8 a $3 \mathrm{~m}$ acima do nível da preamar atual. $\mathrm{Na}$ outra extremidade desse terraço, sobre as margens do rio Mapendipe, perto de Valença (Fig. 3), foi encontrado um outro afloramento oferecendo possibilidades de dataçðes. Este afloramento apresenta na base um sedimento areno-argiloso rico em restos orgânicos, que deve corresponder a uma sedimentação na zona da baixa-mar. Amostras de madeira aí coletadas deram uma idade de $4680 \pm 120$ anos B.P. (Bah. 513). Esses sedimentos são recobertos por areias apresentando estruturas cruzadas e tubos fósseis de Callianassa, tendo sido, portanto, também depositados na zona da baixa-mar. Por fím, no topo da sequência, encontram-se areias sem estruturas aparentes e cujo topo se situa de 2,8 a $3 \mathrm{~m}$ acima do nível da preamar atual. Tendo em vista esse perfil, 
pode-se pensar que em torno de 4.680 anos B.P. o nível médio do mar se encontrava a $2,8 \mathrm{~m} \pm 0,5 \mathrm{~m}$ acima do nível atual. Na região de Valença encontram-se outros terraços arenosos cujos topos se situam de 2,5 a $3 \mathrm{~m}$ acima do nível $\mathrm{da}$ preamar atual.

Entre o morro de São Paulo e a barra do rio Serinhaém (fig. 3), o terraço arenoso holocênico é bem desenvolvido. No exterior do terraço e, provavelmente, em parte recoberto por este, existe um grande recife coralino morto cuja dataça de uma amostra coletada na parte superior deu uma idade de $3180 \pm 60$ anos B.P. (Bah. 515). Nas margens do rio Serinhaém, sobre a formação pleistocênica marinha arrasada, encontra-se um sedimento areno-argiloso rico em restos de madeira. Comparando-se com situaçðes atuais, pode-se concluir que este material se depositou na zona intermaré abaixo da zona ocupada pelas árvores do mangue. Levando em conta que seu topo de encontra a $1 \mathrm{~m}$ acima do nivel da preamar atual, pode-se supor que ele representa um antigo nivel médio marinho situado a $2,5 \pm 0,5 \mathrm{~m}$ acima do nivel médio atual. Essa sequência areno-argilosa é recoberta por 1 $\mathrm{m}$ de areias marinhas.

$\mathrm{Na}$ baia de Camanu (Fig. 3) encontra-se uma série de depósitos arenosos holocênicos situados a aproximadamente $3 \mathrm{~m}$ acima do nível da preamar atual. Mais ao sul, um terraço marinho com cristas de cordðes litorâneos, com largura aproximada de $500 \mathrm{~m}$, se apoia sobre o terraço pleistocênico.

\section{Costa Atlântica entre Itacaré e Ilhéus}

A exceção da região da pequena bacia sedimentar de Almada, essa parte do litoral está situada sobre as rochas precambrianas (Fig. 4). Os depósitos holocênicos aí existen tes são pouco extensos e descontínuos. Entretanto, na região da bacia de Almada, o mar holocênico penetrou bastante no continente, formando uma baía. A pós o máximo da trans. gressão se formaram cordð̌es arenosos que fecharam a baía isolando a laguna de Itaipe (Fig. 4). Sobre os bordos desta existem vestígios de uma formação coralina que foi datada de $4070+140$ anos B.P. (Delibrias e Laborel, 1969). Considerando-se a posição da laguna, é evidente que esses corais só poderiam ter se desenvolvido em uma época de um alto nível marinho.

Na região de Ilhéus foi coletada uma incrustação coralo-. algal indicando um antigo nível médio marinho superior ao nível atual de, pelo menos, 2,5 a $3 \mathrm{~m}$. Nessa regiăo, formacões de arenitos de praia, bem desenvolvidas, e terraços arenosos, testemunham antigos níveis médios marinhos situados acima do nível atual.

\section{DEFORMACÕES DA CROSTA TERRESTRE E DA SUPERFICIE DO GEOIDE NO QUATERNÁRIO}

Se movimentos tectònicos (subsidência, elevação ou basculamento de blocos) ou deformações da superficie do geoide se produziram durante o Quaternário, os testemunhos deixados pelos dois últimos grandes episódios transgressivos que atingiram um nível superior ao nível atual do mar deveriam tê-los registrados.

As variaçoes relativas do nivel médio do mar são a resultante de fenômenos gerais (glacio-eustatismo), de fenômenos locais ou regionais ligados a deformaçoes tectônicas ou isostáticas da crosta terrestre e, também, a deformações da superficie do geoide. Efetivamente, é preciso ter sempre em mente que o nivel médio dos mares é, a cada instante, uma superficie equipotencial do campo de gravidade da Terra. Os deslocamentos de massa no interior da 'Terra poderão gerar deformaçoes na superficie do geoide que, por sua ve\%, 318 poderão se traduzir por efeitos transgressivos ou regressivos. Após medidas de geodésia feitas por satélites, sabe-se que a supertície dos oceanos apresenta elevações e depressões da ordem de mais ou menos $80 \mathrm{~m}$ em relação ao geoide de referência (Gaposchkin, 1973). E sabido que modificações de massa se produziram no interior da Terra ao longo dos tempos geologicos e, portanto, que a forma do geoiđe nao permaneceu a mesma. Mudanças podem ter sido produzidas no sentido vertical (aumento ou diminuição na amplitude das elevacões e depressðes) e/ou no sentido horizontal (translação das elevaçôes e depressðes). Morner (1976) considera que modificações desse tipo podem ter se produzido durante o Holoceno e provocado movimentos locais positivos ou negativos no nível médio dos oceanos. Assim, durante um mesmo período, a componente regional poderá ser positiva, nula ou negativa, segundo a região considerada.

Em certas épocas as variaçóes relativas do nivel médio do oceano podem ter sido muito rápidas. Dessa forma, na Costa do Marfim (Martin, 1973), o nivel médio do oceano passou de $-60 \mathrm{~m}$ a $110 \mathrm{~m}$ entre 23.000 e 18.00 anos B.P. e de $-110 \mathrm{~m}$ a $.10 \mathrm{~m}$ entre 17.000 e 7.000 anos B.P., isto é, en média, uma variação de 10 metros por mil anos. Entretanto, ao longo dos últimos 6.000 anos o nível relativo médio do oceano permaneceu próximo do zero atual, tendo havido provavelmente pequenas oscilações. As grandes variaçð̃es deixaram testemunhos mais ou menos sincrônicos sobre toda a superf́cie da Terra. E lógico portanto de ligá-las ao glacio-eustatismo. Na maioria das vezes, a componente devida a esse fenômeno sendo muito maior do que as componentes regionais ou locais, mascara essas últimas. No entanto, quando a componente glacio-eustática torna-se bastante pequena ou mesmo nula, como parece ter sido o caso para os últimos 6.000 anos, a influência das componentes locais ou regionais pode aparecer nitidamente. Isso pode explicar as diferenças que se nota na parte superior das curvas de variaçao do nível relativo do oceano. Assim, na Holanda, o nivel médio relativo do mar não esteve jamais superior ao nível médio atual durante os últimos 5.000 anos, enquanto que no litoral paulista, nesse mesmo período, o nível médio relativo do oceano se situava entre 3,5 e $4,8 \mathrm{~m}$ acima do nível atual (Suguio, Martin e Flexor, 1977).

E portanto, durante os periodos de estacionamento relativo do nível do mar, correspondentes aos máximos ou mínimos, que se deve procurar as evidências da influência das componentes locais e regionais.

\section{EVENTUAIS DEFORMACÕES DOS DEPÓSITOS MARINHOS PLEISTOCÊNICOS NO LITORAL DA BAHIA}

Os testemunhos deixados pela penúltima grande transgressão sendo constituídos de depósitos arenosos litorâneos (até agora não foram encontrados corais que pudessem ser relacionados a esse episódio e datados pelo método do Urânio/Tório), nao foi ainda possível definir com precisao níveis de referência no tempo e no espaço. Seria perigoso comparar a altitude da parte superior dos diversos testemunhos arenosos encontrados pois não se pode ter certeza de que eles representem o mesmo episódio no tempo e no espaço. Comparando a altitude das regiões contendo tubos fósseis de Callianassa, seria possível correlacionar no espaço os diversos afloramentos, entretanto, o mesmo nåo seria possível quanto ao tempo. $O$ único procedimento válido seria o de tentar comparar a altitude da antiga linha de costa deixada pelo máximo da transgressão em diversos pontos do litoral e de observar as eventuais deformaçoes. No entanto, isso é ben dificil porque, frequentemente, os testemunhos cncontrados nào correspondem a essa linha de máximo. Geralmente eles representam eventos ligeiramente anteriores 
ou posteriores, cujas altitudes serão normalmente diferentes. Assim, sobre o litoral paulista, o topo da Formaçåo, Cananéia (penúltima transgressão) situa-se a $5-6 \mathrm{~m}$ de altitude das zonas externas (próximo ao mar) e a $8-9 \mathrm{~m}$ nas zonas internas (próximo ao cristalino). Ademais, os dados altimé. tricos existentes são insuficientes. As altitudes indicadas sobre os mapas, mesmo os mais necentes, săo bastante imprecisas (foram observadas, por exemplo, regioes de mangue, cujas cotas em mapa assinalam $10 \mathrm{~m}$ ).

Em geral, na regiåo estudada, o topo da formação marinha pleistocênica se situa a aproximadamente $6 \mathrm{~m}$ acima do nivel atual da preamar (7,5 m acima do nível médio). Nas margens do rio Maraú (Fig. 4) a formação é mais baixa, em torno de 4 $m$ acima da preamar. Seria, entretanto, um pouco precipitado entender-se essa diferença de altitude como um argumento em favor de uma deformação tectônica da formação pleistocênica. Na verdade, quando năo se encontram cordões litorâneos na superficie, é possível que o topo da formaçăo arenosa corresponda a um depósito da zona da baixa-mar. Por outro lado, nas regiões contendo cordð̃es, o topo da formação representa um depósito da zona da preamar. Isso pode gerar uma diferença de altitude de 2 a $3 \mathrm{~m}$ para depósitos da mesma idade. Se se compara as zonas sem cordðes ao sul de Maraú e da ilha de Tínharé (Figs. 3 e 4), constata-se uma diferença de altitude de aproximadamente 2 $\mathrm{m}$ (respectivamente 4 e $6 \mathrm{~m}$ acima do nível da preamar). Isso pode ser o indício de uma evolução tectônica ligeiramente diferente devendo-se, porém, considerar essa hipótese com a maior precaução. Com efeito, se se pode admitir que os afloramentos medidos correspondem, nesse caso, a um mesmo ambiente de deposição, podendo desta forma serem definidos no espaço, nåo se conhece, entretanto, a sua posição no tempo. $O$ único dado que pode ser constatado é a ausência da formação marinha pleistocênica em algumas partes do litoral, fato este que pode estar relacionado a uma das três possibilidades seguintes; a) a formação nunca chegou a ser depositada, b) a formação foi depositada e abaixada por fenômenos tectônicos e, c) a formaçăo foi depositada e erodida pela última transgressão. Essa erosão poderia até ter sido facilitada por um abaixamento anterior provocado por eventos tectônicos. Em certos casos, parece que essa ausência seja, na verdade, a consequência de fenômenos tectônicos (subsidência ou basculamento de blocos). Assim, a ausência de testemunhos sobre as margens atuais da Baía de Todos os Santos pode sugerir que a margem atual da baía se situava na época, acina do nível máximo atingido pela penúltima transgressão. Igualmente, a formação da baía de Iguape (Fig. 2), que apresenta características morfológicas de submersăo, parece ter uma origem tectônica bem recente. Entre Valença e Nilo Peçanha (Fig. 3), a zona de depressão situada no pé do cristalino parece ter por origem o afundamento de um bloco limitado, a leste, pelo prolongamento da falha de Maragogipe (Fig. 1) e, a oeste, por uma falha associada que passaria ao pé do cristalino. Ao norte, essa zona seria limitada por uma falha perpendicular que passaria aproximadamente por Valença $e$ o Morro de São Paulo. A presença dessa feiçăo geológica é deduzida das seguintes evidências. Como já apontado ante. riormente, na região entre Valença e a desembocadura do rio Jequiriçá constata-se que os depósitos pleistocênicos eståo deslocados em relação àqueles situados imediatamente ao norte e ao sul (Figs. 2 e 3 ). Nessa região não existe praticamente afloramentos do Cretáceo tendo o mar, durante o máximo da penúltima transgressão, alcançado o pé do cristalino. Em frente a essa parte do litoral encontra-se um vale submarino conhecido cono Canhão de Salvador (Fig. 3). Em alguma época, a cabeça deste canhão deve ter recuado além da linha da costa atual. Esta hipótese se baseia sobre dados de sondagem na região de Guaibim (Fig. 3) que atravessou mais de $70 \mathrm{~m}$ de sedimentos quaternários contendo conchas (CERB, 1975). A escavação desse canhão parece ter sido favorecida por falhas mais ou menos perpendiculares à costa atual, ou pelo basculamento de um bloco que seria limitado, ao sul, por uma falha passando por Valença e o Morro de Sao Paulo (Fig. 3). A zona baixa entre Valença e Nilo Peçanha (Fig. 3) pode igualmente ser explicada pelo basculamento de um bloco cuja parte leste (com depósitos quaternários elevados) estaria em elevação enquanto que a parte oeste (sem depósitos quaternários), estaria em afundamento.

\section{EVENTUAIS DEFORMACÕES DOS DEPÓSITOS MARINHOS HOLOCÊNICOS NO LITORAL DA BAHIA}

Os testemunhos deixados pelos antigos níveis marinhos holocênicos, diferentemente dos pleistocênicos, apresentam a possibilidade de serem em certos casos correlacionados no espaço e no tempo. A comparação da idade e da posição desses testemunhos em diferentes pontos do litoral permitirá, talvez, o estabelecimento de eventuais deformaçoes das antigas linhas de costa holocênicas. $O$ ideal seria construir curvas de variação do nível relativo do mar para diversas zonas do litoral e comparálas. Essas zonas deveriam apresentar características geológicas homogêneas (influência tectônica nula ou igual em toda zona) e serem de pequena extensão para eliminar as variações devidas a deformaçóes na superfície do geoide. Ao que tudo idica, a costa oceânica da cidade do Salvador, situada sobre o precambriano e de pequena extensão satisfaz esses critérios. Logo que se tenha concluído todas as dataçóes para essa parte do litoral, será possível construir uma curva relativa de variação do nível médio do mar para os 6 a 7.000 últimos anos. Os dados de outras partes do litoral que apresentam características geologicas heterogêneas (notadamente a parte da costa situada sobre a bacia sedimentar) poderão ser comparadas a essa cruva de referências.

Os dados até então obtidos são ainda muito poucos, visto que numerosas amostras estão ainda sendo datadas para que se possa definir um traçado para aquela curva. Como um primeiro enfoque, podem-se observar algumas diferenças entre os dados de alguns trechos da área estudada. Assim, os testemunhos mais elevados que foram encontrados a leste da falha de Salvador, sobre o embasamento cristalino, indicam um antigo nível relativo situado a $4,5 \pm 0,5 \mathrm{~m}$ acima do nível médio atual, enquanto que na Baía de Todos os Santos os mesnos não ultrapassam a $3 \pm 0,5 \mathrm{~m}$ acima do nivel médio atual. Vermetidae encontrados na praia do Rio Bermelho (tig. 2) e datados de $1975 \pm 85$ anos B.P. (Bah. 506) indicam um antigo nível relativo a $2,4 \pm 0,5 \mathrm{~m}$ acima do nível médio atual. Na mesma época, na região de Paripe (Fig. 2), o nível nédio relativo se situava ligeiramente acima do nível atual. Também se se comparam entre si dados obtidos em diversos pontos da Baía de Todos os Santos parecem haver diferenças marcantes. Desse modo, o banco de areia fossilizado de lapagipe (Fig. 2), datado de $3270 \pm 145$ anos B.P. (Bah. $415)$, indica um antigo nivel relativo a $1 \pm 0,5 \mathrm{~m}$ acima do nível médio atual, enquanto que na ilha de Madre de Deus o nivel relativo se situava, na mesma época, a $3- \pm 0,5 \mathrm{~m}$. O sambaqui de Pedra Oca (Fig. 2) indica que, neste local da báa, o nivel relativo em torno de 2800 anos B.P. nao devia ser superior a $0.8 \mathrm{~m}$ em relação ao nível atual. Já em itaparica. no local denominado Ponta da Penha (Fig. 2), o nivel relativo cm torno de 2450 anos B.P. se situava a $2 \pm 0.5 \mathrm{~m}$ acima do nível alual. Por tïm, podense considerar que, de uma maneira geral. a ausência de testemunhos de níveis marinhos acima do nivel atual na maior parte da baía, associada ao aspecto atogado da mesma, deve indicar $\mathrm{um}$ afundamento recente dessa região.

Restmindo, pode-se considerar que, levando-se em conta que os diversos testemunhos acima discutidos dispoem-se em 
uma região de pequena extensão, as diferenças nos níveis e idades desses depósitos seriam os primeiros indícios de uma atividade tectônica perceptível na escala do Holoceno.

\section{TENTATIVA DE RECONSTITUIČ̃̃}

\section{PALEOGEOGRÁFICA E PALEOCLIMÁTICA}

A deposição da Formação Barreiras foi precedida de uma grande fase úmida durante a qual se formou um espesso manto de alteração. O clima tornando-se mais seco e contrastado, esse espesso manto de alteração foi erodido e forneceu o material detrítico da Formação Barreiras. Durante a sua deposição o nível do mar encontrava-se mais baixo do que o nível atual, tendo os seus depósitos recoberto uma parte da Plataforma Continental (Bigarella e Andrade, 1965).

$\mathrm{O}$ aparecimento de uma nova fase úmida marcou provavelmente o fím da deposição dos sedimentos do Barreitas. E possivel que os solos ferralíticos que existem no interior do Estado da Bahia, em regioes que apresentam agora um clima muito seco para que eles possam ter sido formados atualmente, datem dessa época. Essa fase úmida foi seguida de um novo período seco e contrastado, durante o qual se formaram os sedimentos continentais posteriores ao Barreiras, mencionados pela primeira vez no presente trabalho e que se encontram em diversos pontos do litoral. Sendo esses depósitos muito menos importantes do que os do Barreiras, é possivel que essa segunda fase seca tenha sido menos longa do que a primeira. Esta deposição em lençol lépandage en nappe") deve ter se produzido em uma época em que o nível do mar estava mais baixo do que o rivel atual, tendo esses sedimentos continentais coberto uma parte da Plataforma Continental. Durante a penúltima transgressão, esses sedimentos retrabalhados pelo mar foram, em parte, a origem do material arenoso dos terraços pleistocênicos. A presença de cristas de cordoes litorâneos ainda nitidamente visíveis nesses terraços, mostra que a superficie dessa formação arenosa permaneceu praticamente sem modificação desde a época de sua deposição. Isso implica na presença de uma cobertura vegetal desde 120.000 anos B.P. nessa parte do litoral e, portanto, que as condiçóes climáticas permaneceram bastante semelhantes ás condições atuais. E possível que pequenas oscilaçðes tenham se produzido, porém, a preservaça dos cordðes pleistocńicos se opð̃e à existência de grandes variacores do tipo precedente.

A medida que se produzia a regressão que seguiu o penúltimo máximo, uma rede hidrográfica se instalou sobre essas areias marinhas escavando pequenos vales. Em torno de 18 a 17.000 anos B.P., a linha da costa se situava aproximada mente sobre a borda da Plataforma Continental $(-110 \mathrm{me}$ tros). A partir dessa época uma transgressåo rápida e bastante regular se produziu. $O$ mar penetrou inicialmente nas zonas baixas formando lagunas. A medida que o nível dc mar ía subindo a formação precedente foi sendo retrabalhada fornecendo o material dos depósitos holocênicos. Entre 7.000 e 6.000 anos B.P. o nível relativo do mar interceptou o zero atual, continuando a se elevar e passando por um ou mais máximos antes de atingir sua posição atual.

\section{CONCLUSÃO}

Durante o Quartenário se produziram um certo número de grandes transgressőes e regressðes. Sobre essa parte do litoral do Estado da Bahia existem, acima do nível médio atual do mar. indiscutíveis testemunhos deixados por dois grandes diferenres episódios transgressivos. Os testemunhos mais antigos datam provavelmente do episódio transgressivo de 120.000 anos B.P. e os mais recentes da parte final da última grande transgressão. Os depósitos mais antigos, sendo essencialmente do tipo areias litorâneas, sem possibilidade, portanto, de datação absoluta, nåo foram passíveis de serem definidos com precisão no espaço e no tempo. A reconstituiçăo de antigas linhas de costa não pode portanto ser feita scnão com a imprecisão de alguns metros. Somente as deformações dessas linhas de costa com amplitude superior a essa imprecisão poderão ser evidenciadas. Os testemunhos mais recentes oferecendo possibilidades de dataçăo ao C14 podem ser definidos com precisão no tempo e no espaço. A reconstituição de antigas linhas de costa poderá ser feita, neste caso, con precisão, como também serem identificadas deformações de pequenas amplitudes. Os primeiros resultados obtidos parecem indicar que as antigas linhas de costa sofreram, segundo a zona do litoral considerada, deformaçôes ligadas a fenômenos de afundamento ou de basculamento de blocos. As deformaçðes da superficie do geoide só poderão ser evidenciadas pela comparação de regióes mais distantes entre si.

A deposição da Formação Barreiras, que se fez sob um clima seco e contrastado foi seguida de uma fase úmida. Após esta fase iniciou-se um novo período de clima seco e contrastado. Durante esse período foi depositada uma formação continental detrítica cujos testemunhos são encontrados em diversos pontos da zona litorânea. Antes do máximo da penúltima transgressão (120.000 anos B.P.) o clima tornou-se novamente úmido. Desde então, sobre essa parte do litoral ele não sofreu variaçōes de grande amplitude. Somente pequenas oscilações que não foram suficientes para gerar o desaparecimento da vegetação devem ter se produrido.

\section{AGRADECIMENTOS}

Os autores querem deixar aqui expressos os seus agradecimentos às entidades financiadoras FINEP e BNDE através do Programa de Pesquisa e Pós-Graduação em Geofísica da UFBa e ao CNPq. Agradecimentos sâo extensivos à $C P R$ (Superintendência Regional de Salvador) por ter colocado à disposição um pequeno barco para deslocamentos na regiăo mapeada.

\section{BIBLIOGRAFIA}

GIBARELLA, J.J. ANDRADE, G.O. 1965, Contributions to the study of the Brazilian Quaternary, Geol. Soc. Amer., Spec. Paper 84: 433-451.

BITTENCOURT, A.C.S.P., FERREIRA, Y.A. e DI NAPOL,, E., 1976, Alguns aspectos da sedimentação na Baía de Todos os Santos, Rev. Bras. Geoc. 6(4): 246-263.

CALDERON, V., 1964, O sambaqui de Pedra Oca, Universidade Federal da Bahia, Instituto de Ciências Sociais, 2.

CERB, 1975, Cadastro de posos tubulares do Estado da Bahia, Companhia de Engenharia Rural da Bahia, CERB, 1, Vol. III, p. 61.

CPRM, 1976, Projeto Narufto, Relatório Final, Superintendência Regional de Salvador, Vol. I (texto), $199 \mathrm{pp}$.

DELIBRIAS, G. e LABOREL, J., 1969. Recent variations of the sea level along the Brazilian coast, VIII Congres Intern. INQUA, Paris, Quaternaria (les niveaux marins holocénes), XVY: $45-49$ (1971).

FERREIRA, Y.A.,1969, Recifes de Arenitos de Salvador, BA, An. Acad. Bras. Cienc. $41(4)$

GAPOSCHKIN, E.M.,1973, Satellite dynamics, in GAPOSCHKIN, E.N., ed. 1973 Smithsonian standard earth (III): Smithsonian Astron. Obs., Spec. Rep. 353:85 - 102.

LABOREL, J., 1967, Les peuplements de madréporaires des côtes tropicales du Brésil, Thése de Doc. d'état présentée à la Faculté des Sciences de l'Université d'Aix, Narseille: 313 pp.

NARTIN, L., 1973, Les variations du niveau de la mer et du climat en Côte d'Ivoire depuis 25.000 ans, Cah. ORSTOm, ser. géol., Vol. IV (2): 93-103

NORNER, N.A., 1976, Eustasy and geoid changes, Journ. Geol, 84(2): $123-151$.

RADIOCARBON,1971, Gif. 878, Vol. 13(2), p. 242, Publicado pela American Journal of Science, Yale University.

SUGUIO, K. e NARTIN, L., 1976, Presença de tubos fósseis de Callianassa nas formaçðes quaternárias do litoral paulista e sua utilizaça xo na reconstrução paleoambiental, Bol. Inst. Geociênc. USP., 7: 17-26, Såo Paulo.

SUGUIO, K., NARTIN, L., FLEXOR,J.N., 1977, Sea level fluctuations during the last 6000 years at the coast of the state of Sao Paulo (Brazil), X Congresso Inter, INQUA, Birminghan (G.B.) Abstract, p. 452, PRE-IMPRESSÃO - Inst. Geociências da USP, São Paulo.

TRICART, J. e CARDOSO DA SILVA, T., 1968, Estudos de geomorfologia da Bahia e Sergipe, Pub. da Fundação para o Desenvolvimento da Ciência na Bahia, 167 pp. 